\title{
Individual differences in stereotypic behaviour predict individual differences in the nature and degree of enrichment use in caged American mink
}

\author{
Jamie A. Dallaire*, Rebecca K. Meagher, Georgia J. Mason \\ University of Guelph, Department of Animal and Poultry Science, 50 Stone Road East, Building \#70, Guelph, Ontario, N1G 2W1, Canada
}

\section{A R T I C L E I N F O}

\section{Article history:}

Accepted 26 September 2012

Available online 23 October 2012

\section{Keywords:}

American mink

Stereotypic behaviour

Establishment

Environmental enrichment

Motivation

Individual variation

\begin{abstract}
A B S T R A C T
Environmental enrichment (EE) reduces stereotypic behaviour (SB), but typically only partially. Using American mink $(n=17)$ as models, we tested the hypotheses that the effectiveness of EE reflects the degree to which subjects utilise it, and also the SB's degree of 'establishment' (its frequency and within-bout predictability). In Non-Enriched cages, our subjects performed Carnivora-typical Locomotor SBs; some also stereotypically scrabbled against the cage walls. Each mink was then enriched: re-housed in a cage connected by an overhead tunnel to a compartment enriched with manipulable objects and running water. Here, both types of SB declined (Locomotor SB: from $5.8 \%$ to $0.9 \%$ of observations; Scrabbling: from $1.6 \%$ to $0.2 \%$ ). Individual differences in these lowered SB levels were stable, correlating positively between observation periods $(\rho \geq+0.66)$. Similar stability was evident in all measures of enrichment use (partial $r \geq+0.74$ ). However, predictions that EE would be least effective for 'established', i.e. highly frequent or predictable, SBs were not supported. Furthermore, nor did low enrichment use predict small reductions in SB: instead, unexpectedly, frequent interactions with enrichment items predicted the smallest absolute reductions in Locomotor SB (partial $r=+0.55$ ). This was because the smallest reductions in this SB occurred in mink with the lowest pre-enrichment levels (partial $r=-0.60$ ), who also interacted most with the enrichments (partial $r=-0.52$ ). Mink with high pre-enrichment levels of Locomotor SB, in contrast, rarely interacted with the enrichments, instead becoming more inactive (partial $r=+0.52$ ). These individuals were also perseverative (displaying more inappropriate response repetition in a previous food-rewarded guessing task), thence potentially behaviourally inflexible. However, their perseveration did not predict less interaction with enrichments. Furthermore, these animals did markedly alter their behaviour when enriched, reducing their SB and shifting their preferred resting locations from home cages to the overhead tunnels (partial $r=+0.70$ ): individual differences that were, again, stable over time (co-variance across observation periods for inactivity in different areas: partial $r \geq+0.65$ ). Individuals thus used enriched environments in consistent, qualitatively different ways that were predicted by pre-enrichment levels of Locomotor SB: low-SB mink became more active when enriched, frequently engaging with manipulable objects and running water, while high-SB subjects instead shifted resting locations and became more inactive. These divergent response styles are unexpected: not predicted by any current understanding of SB. The underlying mechanisms and generality to other species therefore now need investigation.
\end{abstract}

(c) 2012 Elsevier B.V. All rights reserved.

\footnotetext{
* Corresponding author. Tel.: +1 519842 4120x53557; fax: +1 5198369873.

E-mail address: j.ahloy.dallaire@gmail.com (J.A. Dallaire).
} 


\section{Introduction}

Stereotypic behaviour (SB) is a widespread problem in captive animals, and generally indicates that living conditions are sub-optimal for welfare (Mason, 2006; Mason and Latham, 2004). However, ameliorating housing by adding environmental enrichment (EE) typically only partially eliminates the behaviour (e.g. bears: Burghardt, 2005; Meyer-Holzapfel, 1968; horses: Cosyns and Ödberg, 2000; zoo mammals: Shyne, 2006). For instance, EE only halves the time that zoo animals devote to SB (Swaisgood and Shepherdson, 2006). Individuals also generally differ in their responsiveness to EE: for example, EE can largely eliminate SB in some individual laboratory rodents while leaving identicallytreated conspecifics unaffected (Cooper et al., 1996; Hadley et al., 2006; Tilly et al., 2010). This study aimed to investigate why environmental enrichment reduces SB more effectively in some individuals than others, by testing hypotheses concerning the relative attractiveness of enrichments to different individuals, and the nature and correlates of different subjects' SBs prior to enrichment.

Successful environmental enrichments for stereotypic animals generally provide naturalistic stimulation and outlets for normal activities such as foraging (e.g. Swaisgood and Shepherdson, 2006). Proximate causes of SB involve the frustration of specific, highly-motivated behaviour patterns (e.g. Latham and Mason, 2010), along with perseveration: tendencies to repeat actions inappropriately (Dallaire et al., 2011; Garner and Mason, 2002) which become exaggerated by abnormal rearing conditions and/or high levels of stress (e.g. Mason, 2006). Successful enrichments may therefore reduce SB by tackling these underlying causes: thus by reducing overall stress (e.g. Carlstead et al., 1993; Wielebnowski et al., 2002), and/or by facilitating highly motivated behaviours that were previously frustrated (e.g. Bergeron et al., 2006). Enrichments may also reduce SB without addressing these fundamental root causes, but instead simply by providing opportunities to engage in alternative activities which leave animals less time in which to perform SB (e.g. Vickery, 2003)-a 'time-filling' effect that can only be ruled out where SB reduction exceeds time spent interacting with enrichments (Kastelein and Wiepkema, 1989) or remains significant even after statistically controlling for such interaction time (Meehan et al., 2004).

This 'time-filling' hypothesis predicts that enrichments that attract the most time-consuming interaction will most effectively reduce SB. Consistent with this, the amount of time feather-picking parrots spent interacting with foraging enrichments predicted the likelihood that their feather cover would improve (Lumeij and Hommers, 2008). Timeconsuming interaction may also indicate strong underlying motivations to use the newly-added resources (as shown for enrichment objects: Hanmer et al., 2010; also conspecifics: Gibbons et al., 2010; and sucrose: Brennan et al., 2001). Such strong motivations are expected when enrichments successfully reduce overall stress or provide outlets for specific frustrations. However, strong motivations need not always predict large amounts of time spent in interaction: frequent usage may not indicate strong preferences, in environments where there is simply little else to do (Kirkden and Pajor, 2006); and indeed in mink, the time spent using different freely available enrichments did not predict how hard individuals would work for each of them when access was made costly (Mason et al., 1999). Therefore to investigate whether enrichments are most effective when highly preferred, more direct measures of motivational strength than time budgets are needed, such as willingness to pay (e.g. Dawkins, 1983; Kirkden et al., 2003). This willingness to pay approach has been used successfully with laboratory mice: amongst middle-aged females transferred from standard laboratory cages to enriched housing, individuals showing the greatest reductions in SB would also push open the heaviest doors to access the enrichments (Tilly et al., 2010). Our principle aim was thus to test the hypotheses that EEs will best reduce SB when individuals make much use of them and/or are strongly motivated to do so.

However, other specific attributes of the subjects or their SBs may also act to render some SBs resistant to reduction by EE. One is a hypothetical process called 'establishment' (e.g. Mason and Latham, 2004; Ödberg, 1978; Würbel, 2006), wherein repeated performance of SBs renders them both more predictable (reiterations becoming increasingly similar to each other) and less influenced by improvements in welfare (Cronin, 1985; Dodman et al., 2010; Würbel, 2006). This predicts positive associations between the time spent performing SB, the behaviour's spontaneous predictability, and its resistance to enrichment. Though the one relevant study to date (Tilly et al., 2010) found no evidence for this in mice, it is worth testing again using a different species. An additional research aim was therefore to investigate whether the frequency and predictability of SB determine its response to EE.

We chose American mink (Neovison vison) as subjects because they reliably perform SB; the EEs they value are well understood; and they are good models for the Carnivora in general: their SB is primarily locomotor in nature, and peaks shortly before feeding (Hansen et al., 2007; Mason, 1993; Svendsen et al., 2007), as is typical for Carnivore species in zoos and conservation breeding centres (Clubb and Vickery, 2006; Mason et al., 2007). Furthermore, two potential confounding variables are well understood in mink. We have previously shown that the first potential confound, perseveration, does not directly predict the response of SB to EE in mink (Dallaire et al., 2011), but more subtle effects are possible: highly perseverative subjects may still show reduced use of enrichments due to limited behavioural flexibility, potentially contributing to less effective SB reduction. We screened our mink for perseveration to test whether perseverative tendencies compromise EE use. A second known potential confound is hunger. Restricted feeding is known to increase the incidence and frequency of SB in mink (Bildsøe et al., 1991; Damgaard et al., 2004; Mason, 1993). We therefore also tracked feed consumption to determine whether differences in hunger could account for some of the variation in SB in Enriched housing. 
Table 1

Ethogram of mink behaviour.

Locomotor Stereotypic Behaviour (SB)

Normal Activity

Inactivity
Repetitive head/upper body

movements (e.g. bobbing, weaving, repeated either immediately or after a short Scrabbling bout) or locomotive route-tracing (which often includes performance of particular upper body movements or of Scrabbling at fixed areas along the route).

Locomotor $\mathrm{SB}=$ three or more consecutive repetitions

Borderline Locomotor SB = fewer than three consecutive repetitions Subject scrabbles or scratches with forepaws against the plastic walls of the cage or nest box. If Scrabbling occurred as part of a larger sequence of SB (e.g. pace-scrabble-pace), the behaviour was counted in both categories. Any other activity (e.g. walking. sniffing, grooming, eating, drinking, urinating, defecating) Enrichment (E)

Manipulation = subject sniffs or manipulates enrichment objects, dips head into water bath, or engages in any activity inside the water bath

Subject is lying down motionless, expect for minor positional adjustments.

\section{Methods}

The following experiments were approved by the University of Guelph's Animal Care Committee, in accordance with Canadian Council on Animal Care guidelines, and by Michigan State University's Institutional Animal Care and Use Committee.

\subsection{Subjects and housing}

Subjects were mature adult females (two cohorts: 28 months old, $n=10 ; 52$ months old, $n=7$ ) acquired from Michigan State University's Experimental Fur Farm's breeding ranch in East Lansing, Michigan, USA. These were selected from a pool of 31 multiparous adult females, housed on the farm in individual whelping cages (wire mesh, with rigid plastic side walls: $W 61 \mathrm{~cm} \times \mathrm{D} 76 \mathrm{~cm} \times \mathrm{H} 46 \mathrm{~cm})$ with external nest boxes (wooden, with wire mesh top) $(\mathrm{W} 37 \mathrm{~cm} \times \mathrm{D} 24 \mathrm{~cm} \times \mathrm{H} 28 \mathrm{~cm})$. We focused on mature animals as more likely to have enrichment-resistant SB (Cooper et al., 1996; Tilly et al., 2010); and were constrained to females only because male mink are typically killed for their pelts before a year old. All 31 females were observed for SB over 4 days, between February 25th and March 1st, for a total of 54 instantaneous scans during 12.5 pre-feeding hours (see Table 1 for ethogram). Twenty-one of them were seen performing Carnivora-typical Locomotor SB or Borderline Locomotor SB at least once, but four died before the start of our experiment, leaving us with 17 stereotypic subjects. During these preliminary screens, our

17 subjects performed these SBs for a combined average of $22.6 \%$ of observations (range 1.9-64.8\%). Some also showed Scrabbling (see Table 1) for an average of $5.2 \%$ (range 0-38.9\%).

Just before our experiment, in August, subjects were moved to a climate-controlled indoor facility with an artificial light cycle yoked to sunrise and sunset times, where they were again individually caged. Drinking water was provided ad libitum via a water line and nipple drinker, and all animals were fed c. $150 \mathrm{~g}$ of standard mink feed (a meat-based paste) once a day, between 12:00 and 13:00 h. From August to December, all subjects were kept in NonEnriched (NE) housing, which consisted of a home cage (wire mesh, with rigid plastic side walls) with external nest box (wooden on sides; plastic on front, back, and bottom; wire mesh on top) (shaded areas in Fig. 1a and b). In November, all subjects were made to perform a guessing task in an operant apparatus to assess recurrent perseveration. This was quantified using three different mathematical indices of response patterning (Dallaire et al., 2011 gives details).

In December, all subjects were transferred to Enriched (E) housing: this comprised a home cage plus nest box as in NE housing, with additional access to a second, larger wire mesh cage (Fig. 1a and c) containing a variety of manipulable objects (e.g. balls, plastic pipes or tubes, chewable items), a rigid plastic shelf-like hammock, and a $120 \mathrm{~cm}$ long by $5-10 \mathrm{~cm}$ deep trough of circulating filtered water. Mink are semi-aquatic (Dunstone, 1993) and are highly motivated to access water baths (Mason et al., 2001); their Locomotor SBs are reduced by a combination of tubes, balls and chewable ropes (Hansen et al., 2007); and these particular enriched compartments had previously been shown to reduce $\mathrm{SB}$ and corticosteroid hormone output (Díez-León and Mason, 2010; Meagher, 2011). Access from the home cage was by climbing a tower using wire mesh ramps, traversing a $3 \mathrm{~m}$ wire mesh overhead tunnel, and descending an identical tower with identical ramps. To facilitate evaluation of enrichment use and keep it confined to the EE compartment, all manipulable objects small enough to be pulled into the tower were attached to the walls using long pieces of flexible metal wire, ensuring that they could be manipulated and carried, but not dragged out of the enriched compartment.

\subsection{Behavioural observations}

Behavioural observations were conducted over 6 days during each of three periods (September 22nd to 26th ( 5 days only), October 19th to 24th, December 9th to 16th) in Non-Enriched (NE) housing; and two periods in the following calendar year (February 5th to 10th, and February 27th to March 4th) in Enriched (E) housing. The first author conducted all observations except for one period (September), covered by Meagher. Observed frequencies co-varied between observers (e.g. $r=+0.54, P=0.026$ for Locomotor SB, September vs. [October + December]) and thus were pooled for subsequent analyses. Individual scores for each behaviour type were obtained by averaging across all periods in a given housing condition. Subjects were given a new type of manipulable object on the 

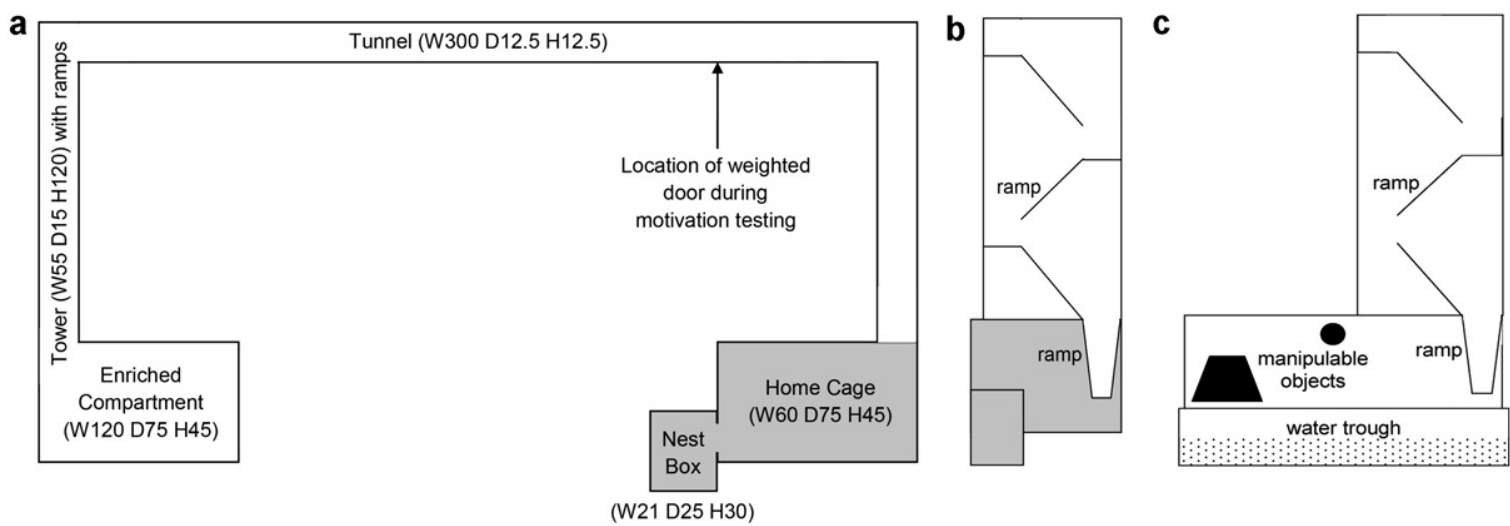

Fig. 1. Schematic of mink cages, with dimensions in $\mathrm{cm}$. (A) Side view. (B) Frontal view of home cage, nest box, and tower. (C) Frontal view of enriched compartment and tower.

afternoon preceding the start of each of the two E observation periods. Those objects that were already present were not removed. Subjects were given new, randomly chosen identity cards after transfer to $E$ housing, to ensure observer blindness to levels of SB in NE conditions. We used a modified type of instantaneous scan sampling (Martin and Bateson, 2007), observing each animal once every $9 \mathrm{~min}$ during the $3 \mathrm{~h}$ immediately preceding scheduled feeding, each time recording the behaviour being performed at the end of a $10 \mathrm{~s}$ observation period, which allowed us to gauge the repetitiveness of behaviours. This observation period was chosen because stereotypic behaviour peaks before mealtime in mink (Hansen et al., 2007; Mason, 1993; Svendsen et al., 2007). Direct observation has negligible effects on mink behaviour compared to video recording (Svendsen et al., 2007). Behaviours were classified according to the ethogram in Table 1. Predictability was calculated as Locomotor SB divided by [Locomotor SB + Borderline Locomotor SB] (cf. Tilly et al., 2010). Predictability was not calculated for Scrabbling because repetitions were too fast to count reliably.

Note that Scrabbling was treated separately from Locomotor SB for three reasons. First, unlike Locomotor SB, it often appears to be directed at other mink, and previous authors have reported that similar "scratching" seems to be an attempt to enter areas to which access is denied (nest box: Hansen and Jeppesen, 2000; mother: Houbak and Jeppesen, 1987, cited in Akre et al., 2008). Second, unlike Locomotor SB, it does not correlate with recurrent perseveration (Dallaire et al., 2011). Third, unlike Locomotor SB, Scrabbling is not widely reported across captive Carnivora.

Enrichment use was quantified in three ways, in each case as a proportion of each subject's overall pre-feeding time budget. First, we measured 'Presence in E housing': the time spent in enriched areas (enriched compartment, towers and tunnel, all previously unavailable in NonEnriched housing; non-shaded zones in Fig. 1a). Second, we calculated 'Activity in E housing': the time spent performing normal (non-SB) activities in these same areas, reflecting only active use of enrichment items, structures, and/or E space (e.g. climbing ramps, manipulating objects, traversing tunnels, entering water). Finally, we measured 'E Manipulation': the time spent directly interacting with enrichment items or water (Table 1), excluding other types of normal activities in enriched areas. These three different measures thus successively assessed more direct, unambiguous types of enrichment use.

All subjects were given similar daily food rations regardless of individual feed intake. This corresponded to ad libitum feeding for some individuals, while others likely experienced this regime as semi-restricted feeding. To control for differences in hunger, we counted the number of behavioural observation days in E housing on which each subject failed to consume her entire food ration.

\subsection{Assessment of motivation for enrichment}

In March and April, after behavioural observations, we assessed motivational strength by placing a weighted door in the tunnel leading to the E compartment (Cooper and Mason, 2001; Mason et al., 2001). Maximum price paid (MPP), used to assess motivational strength, is obtained by imposing a series of costs on access to a resource and recording the maximum cost an animal is willing to pay (Hovland et al., 2006; Kirkden et al., 2003). Because individual differences in MPP for a given resource may also reflect non-motivational factors (e.g. physical strength), it is advisable to statistically correct for MPP for a different, highly valued resource, like food (cf. e.g. Dawkins, 1983; Olsson and Keeling, 2002; Seaman et al., 2008). A weightable door was installed inside each subject's tunnel, near the top of the tower above its home cage (Fig. 1a), while a second door, which could only be opened from one side, allowed free (unweighted) passage from the enriched compartment back to the home cage. Mink were allowed to habituate to these doors for 17 days before any weight was added. The weight of each subject's door was increased by $250 \mathrm{~g}$ every morning if she had walked through it during the previous day, until the subject failed to open the door for an entire day; the highest mass pushed was recorded as her MPP for enrichment. Passage through the weighted door was verified using strips of paper pulled taut beyond it; mink could not get to the enriched compartment without breaking the paper. We also separately measured MPP for food, after moving the pair of doors to a short tunnel leading to a previously inaccessible empty neighbouring home cage, 
in which mink received all their daily meals from then on. Mink were allowed to habituate to the doors and the new location of food delivery for 12 days before weights were added. Due to time constraints, we added $500 \mathrm{~g}$ daily when testing MPP for food, only dropping to $250 \mathrm{~g}$ increments once a subject was within $750 \mathrm{~g}$ of her MPP for enrichment.

\subsection{Statistical analyses}

All tests were run in Minitab 15, using $\alpha=0.05$. To evaluate housing effects on behaviour, we ran repeated measures ANOVAs using Type III (Adjusted) SS, with housing (E vs. NE) as the repeated factor. Mink identity (random variable nested within cohort), cohort, and interactions between cohort and housing were also included as factors. Analogous ANOVAs were used to test for an effect of resource type (enrichment vs. food) on MPP; to compare absolute changes in SB to time spent in E Manipulation; and to compare time budgets between different observation periods in $\mathrm{E}$ housing. Where the presence of too many zero values made residuals non-normal, we instead used Wilcoxon matched-pairs signed rank tests, run by hand. Due to the presence of tied ranks, $P$ values for the Wilcoxon test are a Gaussian approximation. Sample-wide correlations were tested for in General Linear Models, with cohort as a factor, using Type II (Adjusted) SS. The stability of individual differences in behaviour over the two periods of observation in E housing was assessed by testing for such correlations between both observation periods (February 5 th to 10 th vs. February 27 th to March 4 th) or, where too many zeros made residuals non-normal, using Spearman's rank correlation. In all ANOVAs and GLMs, proportions of time spent performing a given behaviour (e.g. SB) were arcsin-square root transformed to normalize residuals.

Where change in SB (Locomotor SB or Scrabbling) was the dependent variable, it was quantified in four different ways (modified from Tilly et al., 2010): (a) absolute change in $S B$ frequency $(E-N E$ ), (b) relative change in SB frequency (E/NE), (c) residual change in SB frequency (residuals of a regression of SB in E housing on SB in NE housing), and (d) in a GLM with SB in E as the dependent variable and $\mathrm{SB}$ in NE as a covariate. The latter is conceptually equivalent to residual analysis, but avoids problems associated with this approach, including overestimation of degrees of freedom and bias in cases where other variables affect the dependent variable (Darlington and Smulders, 2001; García-Berthou, 2001).

To assess whether individual differences in hunger could be a confound explaining some of our results, all GLMs were re-run in two ways: first, adding the number of days on which a subject did not consume her entire food ration in Enriched housing as a covariate (and its interaction with cohort); second, without this covariate but after removing the two outliers responsible for a negative relationship between food-leaving and SB in E housing (see below).

\section{Results}

Throughout this section, effects of cohort and its interactions are non-significant unless otherwise specified.
Partial sub-sample means presented with GLM results were obtained as follows: the independent and dependent variables were separately regressed against cohort and any other factors or covariates in the model, and their residuals were then corrected for range, by adding each variable's sample-wide mean. Partial correlation coefficients (partial $r$ ) were calculated between residuals obtained in the same manner. All scatter plots show partial regressions between these residuals, corrected for range as above. When plotted variables had been arcsin-square root transformed for analysis, the corresponding axis is scaled accordingly to show individually back-transformed values for each data point.

\subsection{Behavioural changes in Enriched housing}

Following transfer from Non-Enriched to Enriched housing, all mink used the enriched areas (means $\pm \mathrm{SE}$ for Presence in E: $59.3 \%$ of total time budget, backtransformed from $0.879 \pm 0.090$; Activity in E: $17.8 \%$ back-transformed from $0.435 \pm 0.029$ ), and all but one mink interacted directly with objects and water to some degree (E Manipulation: 4.1\% back-transformed from $0.203 \pm 0.023$ ). Behavioural time budgets, averaged over all subjects, are shown in Fig. 2; they do not sum to $100 \%$ in each housing condition due to back-transformation and because some types of behaviour (e.g. Scrabbling at fixed locations within a repetitive pacing route) were counted as both Locomotor SB and Scrabbling (see Table 1). As expected, in Enriched housing, subjects showed less frequent Locomotor SB $\left(F_{1,15}=10.35, P=0.006\right)$ and Scrabbling $\left(F_{1,15}=14.64, P=0.002\right)$, and more Normal Activity $\left(F_{1,15}=8.19, P=0.012\right)$, than in Non-Enriched housing, with no overall difference in Inactivity $\left(F_{1,15}=0.03\right.$, $P=0.854)$. The decreases in SBs following transfer to Enriched housing were not merely due to 'time filling' effects: they remained significant even when (i) SBs' frequencies were recalculated as a proportion of all time excluding E Manipulation, rather than of the entire time budget (cf. Kastelein and Wiepkema, 1989) (Locomotor SB: NE: $5.8 \%$ back-transformed from $0.243 \pm 0.023$; E: $1.0 \%$ back-transformed from $0.100 \pm 0.023 ; F_{1,15}=9.51$, $P=0.008$; Scrabbling: NE: $1.6 \%$ back-transformed from $0.125 \pm 0.010 ; \mathrm{E}$ : $0.3 \%$ back-transformed from $0.050 \pm 0.010 ; F_{1,15}=13.67, P=0.002$ ), and also when (ii) E Manipulation was statistically controlled for as a GLM covariate (cf. Meehan et al., 2004) (Locomotor SB: NE: $4.0 \%$ back-transformed from $0.202 \pm 0.025$; E: $1.9 \%$ backtransformed from $0.137 \pm 0.025 ; F_{1,14}=15.98, P=0.001$; Scrabbling: NE: $0.9 \%$ back-transformed from $0.097 \pm 0.011$; E: $0.6 \%$ back-transformed from $0.076 \pm 0.011 ; F_{1,14}=4.75$, $P=0.047$ ).

The amount of change in Locomotor SB and Scrabbling in mink moved from NE to E housing was highly variable between individuals. To illustrate, 11 of the $17 \mathrm{sub}$ jects showed reduced Locomotor SB in Enriched housing (including seven in which it was abolished), three showed no Locomotor SB in either type of housing, and three others actually performed more Locomotor SB in E than in NE housing. Absolute changes in Locomotor SB thus ranged from a $16.8 \%$ decrease (from $16.8 \%$ to $0.0 \%$ of an individual's time budget) to a $14.5 \%$ increase (from $8.4 \%$ to 


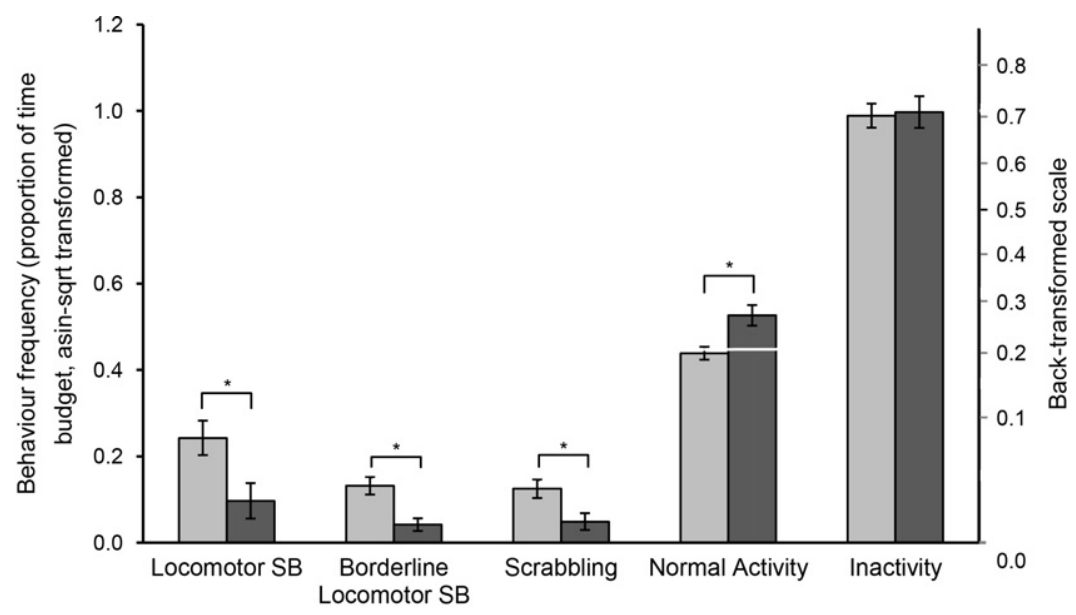

Fig. 2. Stereotypic (SB) and other behaviour (mean \pm SE) in Non-Enriched (light bars) and Enriched (dark bars) housing (mean $\pm \mathrm{SE}$ ). The white horizontal bar shows the level of Normal Activity excluding Enrichment (E) Manipulation.

22.9\%). These individual differences in Enriched housing were stable over time. Thus, the amount of Locomotor SB was consistent between the two observation periods, taken 4 weeks apart $(\rho=+0.80, P<0.001)$, as was the amount of Scrabbling $(\rho=+0.66, P=0.004)$. Levels of EE use were also stable, co-varying between the first and second observation periods (for all three measures: partial $r \geq+0.740$, $\left.F_{1,13} \geq 16.58, P \leq 0.001\right)$.

\subsection{Relationships between $S B$ reduction and pre-enrichment SB frequency or predictability}

Pre-enrichment levels of both SB types predicted one measure of the impact of EE on SB, but not in the direction predicted: mink who had shown frequent Locomotor SB or Scrabbling in NE showed the largest absolute declines in these behaviours (Table 2). This reflects a floor effect: most individuals who showed very little absolute reduction in SB did so because they had performed very little SB in NE housing. Mink who spent the most time performing Locomotor SB in Non-Enriched housing were also those whose Locomotor SB was most predictable (partial $\left.r \geq+0.84, F_{1,11}=28.05, P<0.001\right)$. Thus, the same floor effect explains why higher predictability also tended to correlate with larger absolute decreases in Locomotor SB (Table 2): again, the opposite of what was predicted.

\subsection{Relationships between $S B$ reduction and motivation to reach enrichments}

Subjects were highly motivated to reach the enriched compartment: MPP for enrichment, averaging $1426 \pm 173 \mathrm{~g}$, was as high as MPP for food, which averaged $1338 \pm 140 \mathrm{~g}$, the difference between them being non-significant $\left(F_{1,15}=0.68, P=0.423\right)$. However, individual differences in MPP for enrichment, corrected for MPP for food, showed no relationships with reduction of SB by EE $(P>0.05$ for both SBs and all methods of quantifying change).

\subsection{Enrichment use and its relationship to $S B$ reduction and to perseveration}

No measures of enrichment use correlated with change in Locomotor SB or Scrabbling in the expected direction (Table 3), regardless of the method used to quantify change. We found two sets of significant correlations, both in unexpected directions. First, mink who spent more time

Table 2

Summary of relationships between properties of stereotypic behaviour (SB) in Non-Enriched housing (NE) and its reduction by environmental enrichment (a negative relationship means that a high value of the independent variable [column headings] predicts a large decline in SB).

\begin{tabular}{|c|c|c|c|}
\hline & Locomotor SB in NE (\% total time) & Predictability of Locomotor SB in NE & Scrabbling in NE (\% total time) \\
\hline $\begin{array}{l}\text { Absolute change in this } \\
\text { SB }\end{array}$ & $\begin{array}{l}\text { partial } r=-0.595 \\
F_{1,13}=7.24 \\
P=0.018\end{array}$ & $\begin{array}{l}\text { partial } r=-0.481 \\
F_{1,11}=3.42 \\
P=0.091\end{array}$ & $\begin{array}{l}\text { partial } r=-0.799 \\
F_{1,13}=31.40 \\
P<0.001\end{array}$ \\
\hline $\begin{array}{l}\text { Relative change in this } \\
\text { SB }\end{array}$ & $\begin{array}{l}\text { partial } r=-0.056 \\
F_{1,9}=0.03 \\
P=0.869\end{array}$ & $\begin{array}{l}\text { partial } r=-0.382 \\
F_{1,9}=1.57 \\
P=0.242\end{array}$ & $\begin{array}{l}\text { partial } r=-0.325 \\
F_{1,10}=1.21 \\
P=0.296\end{array}$ \\
\hline $\begin{array}{l}\text { Residual change in this } \\
\text { SB }\end{array}$ & - & $\begin{array}{l}\text { partial } r=-0.166 \\
F_{1,11}=0.32 \\
P=0.585\end{array}$ & - \\
\hline $\begin{array}{l}\text { GLM method for } \\
\text { change in this SB }\end{array}$ & - & $\begin{array}{l}\text { partial } r=-0.358 \\
F_{1,10}=1.55 \\
P=0.241\end{array}$ & - \\
\hline
\end{tabular}


Table 3

Summary of tests of relationships between enrichment (E) use and changes in stereotypic behaviour (SB).

\begin{tabular}{|c|c|c|c|c|}
\hline & \multicolumn{4}{|c|}{ Change in Locomotor SB } \\
\hline & Absolute change & Relative change & Residuals method & GLM method \\
\hline \multirow[t]{3}{*}{ Presence in E housing } & partial $r=-0.297$ & partial $r=+0.133$ & partial $r=+0.075$ & partial $r=+0.107$ \\
\hline & $F_{1,13}=1.26$ & $F_{1,9}=0.16$ & $F_{1,13}=0.07$ & $F_{1,12}=0.14$ \\
\hline & $P=0.282$ & $P=0.696$ & $P=0.789$ & $P=0.716$ \\
\hline \multirow[t]{3}{*}{ Activity in E housing } & partial $r=+0.221$ & partial $r=+0.367$ & partial $r=+0.328$ & partial $r=+0.327$ \\
\hline & $F_{1,13}=0.70$ & $F_{1,9}=1.44$ & $F_{1,13}=1.57$ & $F_{1,12}=1.44$ \\
\hline & $P=0.417$ & $P=0.262$ & $P=0.232$ & $P=0.253$ \\
\hline \multirow[t]{5}{*}{ E Manipulation } & partial $r=+0.550$ & partial $r=+0.376$ & partial $r=+0.366$ & partial $r=+0.414$ \\
\hline & $F_{1,13}=6.01$ & $F_{1,9}=1.61$ & $F_{1,13}=2.03$ & $F_{1,12}=2.50$ \\
\hline & $P=0.029$ & $P=0.236$ & $P=0.178$ & $P=0.140$ \\
\hline & \multicolumn{4}{|c|}{ Change in Scrabbling } \\
\hline & Absolute change & Relative change & Residuals method & GLM method \\
\hline \multirow[t]{3}{*}{ Presence in E housing } & partial $r=+0.208$ & partial $r=+0.173$ & partial $r=+0.361$ & partial $r=+0.376$ \\
\hline & $F_{1,13}=0.61$ & $F_{1,10}=0.32$ & $F_{1,13}=2.11$ & $F_{1,12}=2.12$ \\
\hline & $P=0.447$ & $P=0.585$ & $P=0.170$ & $P=0.171$ \\
\hline \multirow[t]{3}{*}{ Activity in E housing } & partial $r=+0.264$ & partial $r=+0.290$ & partial $r=+0.539$ & partial $r=+0.539$ \\
\hline & $F_{1,13}=0.98$ & $F_{1,10}=1.09$ & $F_{1,13}=6.58$ & $F_{1,12}=6.10$ \\
\hline & $P=0.340$ & $P=0.321$ & $P=0.024$ & $P=0.029$ \\
\hline \multirow[t]{3}{*}{ E Manipulation } & partial $r=+0.168$ & partial $r=+0.213$ & partial $r=+0.288$ & partial $r=+0.289$ \\
\hline & $F_{1,13}=0.38$ & $F_{1,10}=0.48$ & $F_{1,13}=1.18$ & $F_{1,12}=1.10$ \\
\hline & $P=0.550$ & $P=0.504$ & $P=0.297$ & $P=0.315$ \\
\hline
\end{tabular}

performing non-stereotypic activities in enriched areas (Activity in E) also showed more Scrabbling (not less, as predicted) in Enriched housing than expected based on their Scrabbling in Non-Enriched housing (residual and GLM methods). Second, mink who interacted with objects and water (E Manipulation) the most also showed the smallest absolute reductions (not the greatest, as expected) in Locomotor SB (Fig. 3).

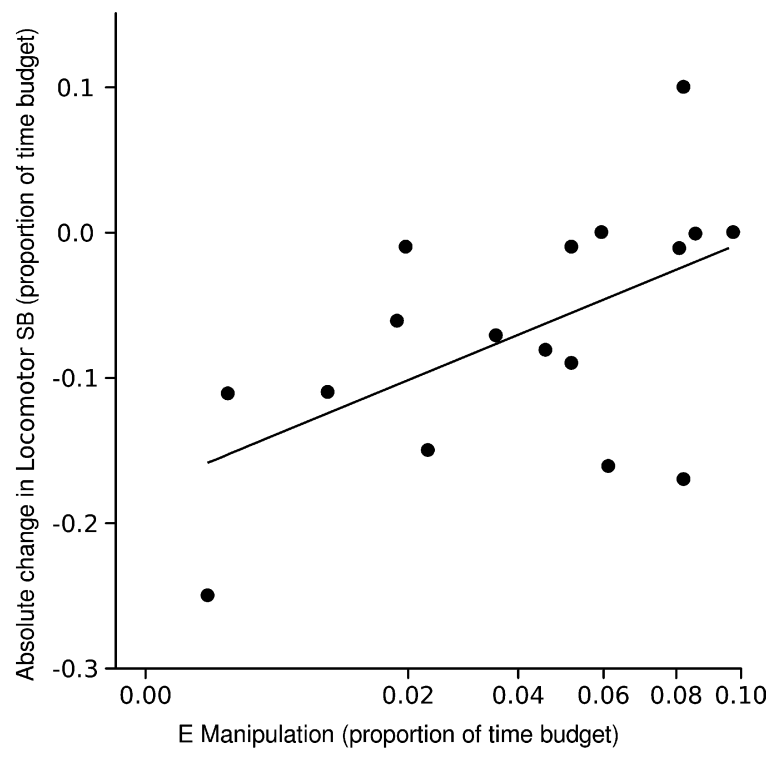

Fig. 3. Enrichment (E) Manipulation in Enriched housing and absolute change in Locomotor Stereotypic Behaviour (SB) from Non-Enriched to Enriched housing.
Individual differences in enrichment use could not be explained by differences in perseveration. Only one of our three indices of recurrent perseveration, "Detrended Fluctuation Analysis" (Dallaire et al., 2011), tended to negatively correlate with one measure of E-use: E Manipulation (partial $r=-0.43, F_{1,13}=3.29, P=0.093$ ). There were no similar effects for our other measures of recurrent perseveration, or our other measures of enrichment use. Furthermore, as explored in Section 3.5, mink with high pre-enrichment levels of Locomotor SB and thence high perseveration did not seem behavioural inflexible when offered enrichment: they showed great changes in behaviour, albeit not in expected ways.

\subsection{Exploratory analyses: why was low usage of enrichment related to small declines in $S B$ rather than large declines in $\mathrm{SB}$ ?}

We ran additional post hoc analyses to understand why the only significant relationships between EE use and SB reduction were in the opposite directions to those predicted. First, the positive relationship between Activity in E - the active time spent in the enriched compartment, towers, and tunnel, excluding SB - and residual/GLM change in Scrabbling seemed to be due to a tight positive relationship between Activity in E and overall activity levels, including SB and disregarding location (partial $r=+0.74$, $F_{1,13}=15.63, P=0.002$ ), which in turn tended to be positively correlated to Scrabbling in Enriched housing, at least in the older cohort (interaction between overall activity and cohort: $F_{1,13}=4.54, P=0.053$; older cohort: $r=+0.67$, $P=0.099$; younger cohort: $r=+0.31, P=0.383$ ). When Activity in E housing was therefore re-calculated as a proportion of overall activity, instead of as a proportion of total 


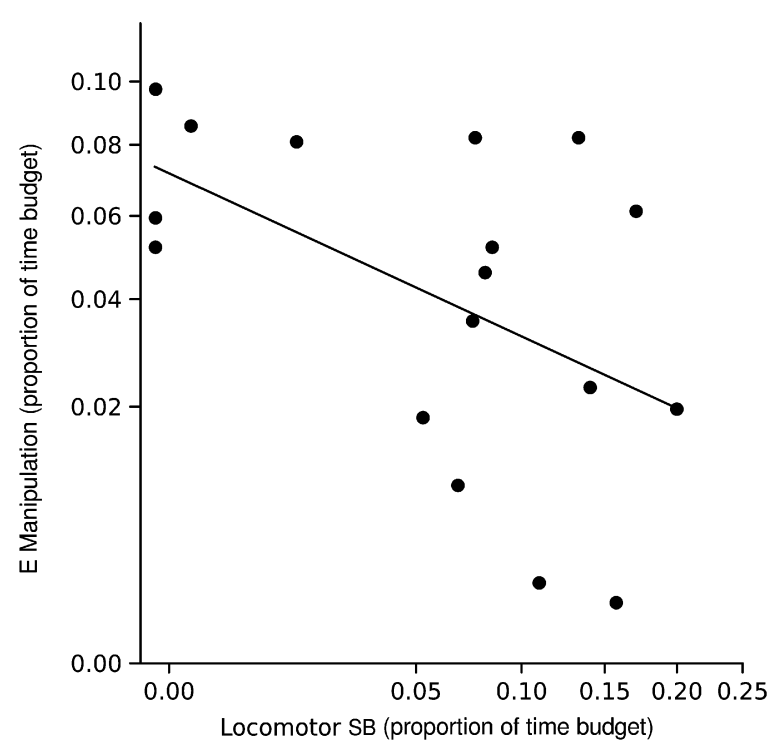

Fig. 4. Locomotor Stereotypic Behaviour (SB) in Non-Enriched housing and Enrichment (E) Manipulation in Enriched housing.

time, its relationship to change in Scrabbling became nonsignificant.

The second unexpected result was the relationship between high E Manipulation and smaller absolute decreases in Locomotor SB. This also proved simply an artefact of other existing relationships. We had found that smaller absolute changes in this SB were linked with lower pre-enrichment levels of the behaviour (Section 3.4; Table 3), and further tests showed that Locomotor SB in Non-Enriched housing negatively predicted E Manipulation (partial $r=-0.52, F_{1,13}=4.74, P=0.049$; Fig. 4). Thus, mink with large reductions in Locomotor SB in $E$ housing were those who had frequently performed this SB in Non-Enriched housing, and who correspondingly showed low E Manipulation. We therefore investigated how the mink who had performed the most Locomotor SB in Non-Enriched housing were spending their time once in Enriched housing, given that they rarely manipulated enrichments yet still performed less Locomotor SB than before. We found that Locomotor SB in Non-Enriched housing positively predicted the amount of absolute change in inactivity from Non-Enriched to Enriched housing (partial $r=+0.52, F_{1,13}=4.77, P=0.048$ ). This absolute change in inactivity was negatively correlated to E Manipulation (partial $r=-0.83, F_{1,13}=35.00, P<0.001$; Fig. 5). Thus, the mink who had performed the most Locomotor SB in NonEnriched housing became increasingly inactive in Enriched housing, rather than interacting with enrichment objects.

We next tested the post hoc hypothesis that these formerly high-SB mink used the enriched environments to display inactivity in new, formerly unavailable, locations (i.e. the overhead tunnels and towers). Locomotor SB in Non-Enriched housing positively correlated with the time spent inactive in Enriched housing in the towers and tunnel (partial $r=+0.70, F_{1,13}=12.36, P=0.004$ ), and negatively correlated with the time spent inactive in Enriched housing in the home cage and nest box (partial $r=-0.63, F_{1,13}=8.42$,

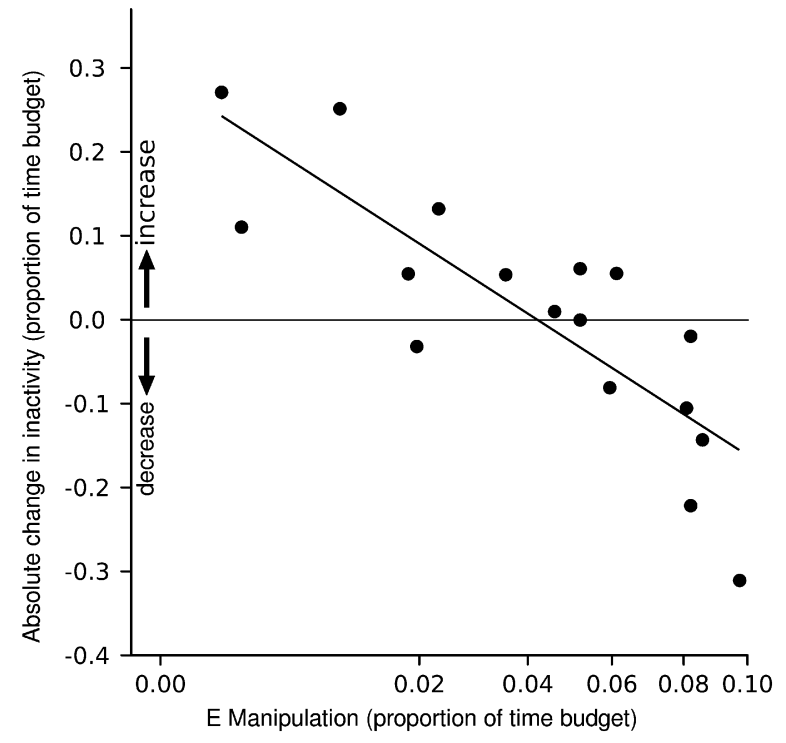

Fig. 5. Enrichment (E) Manipulation in Enriched housing and absolute change in inactivity from Non-Enriched to Enriched housing.

$P=0.012$; Fig. 6): sites that had been the only available locations for resting pre-enrichment. As for all our other effects, these enrichment effects on inactivity were stable over time: thus measures of time spent inactive, whether in total, in the tower and tunnel, or in the home cage and nest box, co-varied between the two observation periods (partial $r \geq+0.648, F_{1,13} \geq 9.50, P \leq 0.009$ ).

Thus, to summarise results: following the move to Enriched housing, mink who had previously had high levels of Locomotor SB in Non-Enriched housing consistently and stably replaced this behaviour with inactivity, particularly in the towers and tunnels that we had assumed would

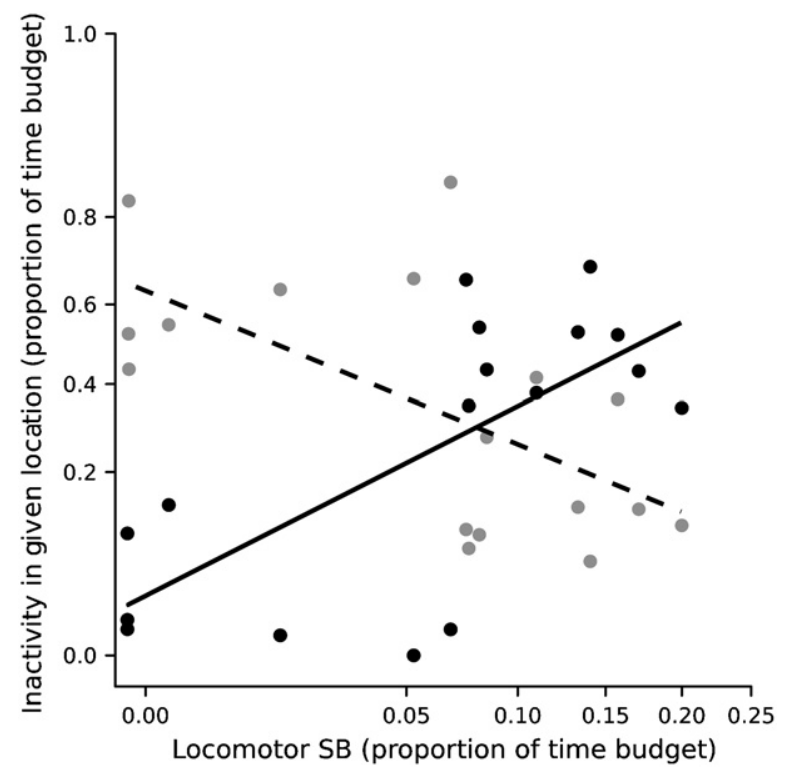

Fig. 6. Locomotor Stereotypic Behaviour (SB) in Non-Enriched housing and time spent inactive in the towers and tunnel (dark circles; solid line) and in the home cage and nest box (light circles; dashed line). 
be used mainly as access routes to the enrichment compartment. In contrast, the mink with initially low levels of Locomotor SB became consistently and stably more active, substituting interaction with the enrichment items and running water for their formerly high levels of inactivity.

\subsection{Was differential hunger a confound?}

There was a significant negative relationship, in Enriched housing, between the number of days each individual did not consume her entire food ration and SB (partial $r=-0.57, F_{1,13}=9.35, P=0.009$ ). However, rerunning all our analyses with this number included as a covariate in all GLMs produced no substantive changes to any result. Furthermore, the relationship between foodleaving and SB depended on two statistical outliers (via the boxplot test), and was non-existent without them (partial $r=-0.04, F_{1,13}=0.02, P=0.901$ ). Excluding these and re-running all analyses again resulted in no substantive changes to results. Thus differential feeding motivation was not a confound responsible for our results.

\section{Discussion}

Just as anticipated, Carnivore-typical Locomotor SBs and stereotypic Scrabbling were substantially reduced, but overall not abolished, after transfer to large, complex enriched environments; furthermore, individuals varied greatly in the extent of this reduction. However, none of our hypotheses as to why enrichment varies in its effectiveness at SB reduction were supported. First, mink with high levels of SB or very predictable forms of this behaviour (two traits that co-varied, as predicted by ideas about SB 'establishment') did not have particularly EE-resistant SB. Thus, as also found by Tilly et al. (2010) in mice, SBs that might be described as established were no harder to tackle with enrichment than less frequently performed or more variable SBs. (We could not test the influence of another factor potentially contributing to establishment - the length of time an animal has been performing SB - because our older cohort were not just older: they had been through more rounds of selection for good breeding than had our younger cohort, and so were not a random subset of animals). Second, turning to another of our main hypotheses, reductions in SB were not predicted by high motivations to reach enrichments. However, this finding is almost certainly invalid because our weighted door test did not adequately reflect motivation to reach towers and access tunnels, in which some mink spent large amounts of time resting (an issue discussed further below). Third, our hypothesis about the correlates of high E-use was also rejected: extensive use of the enrichments was related to smaller absolute reductions in Locomotor SB, rather than larger ones. This unexpected result proved to be related to the way some mink used the towers and tunnels for resting rather than interacting with objects and water, and was particularly intriguing. It is now discussed in more detail.

Mink who had frequently performed Locomotor SB in Non-Enriched housing performed much less of it in Enriched housing despite interacting very little with objects and water; instead they became highly inactive, and preferentially rested in enriched, elevated areas. In contrast, mink with infrequent Locomotor SB in NE housing still rested in their original home cage or nest box when given access to the E compartment; they also became much more active and spent much time interacting with enrichment objects and water. Furthermore, not only were these responses to environmental enrichment heterogeneous across mink: they were also temporally stable within each mink, with distinct behavioural syndromes present. These divergent response styles were not predicted by any current understanding of SB.

The mechanisms underlying enrichment-enhanced inactivity, a phenomenon apparently specific to formerly highly stereotypic animals, now need further investigation. Our elevated towers and tunnels had similar effects to the raised shelves used in previous studies of stereotypic mink, which have been found to increase inactivity and to reduce stereotypic behaviour (Axelsson et al., 2009; Hansen, 1990; Hansen et al., 2011). This suggests that access to preferred resting sites is particularly important in stereotypy reduction for some mink. However, we do not as yet know what makes certain sites more valuable than others, or why this differs between individuals. With respect to our elevated, enriched areas, one possibility is that they provided a refuge from human handlers, who could only catch mink by opening the home cage or enriched compartment, thus simultaneously promoting inactivity and reducing Locomotor SB by decreasing stress and vigilance - however, contrary to what this would predict, existing studies suggest that highly stereotypic animals tend to be bold, not the most fearful (Hansen and Jeppesen, 2006). It could instead be that these mink used elevated areas as vantage points from which to passively monitor their surroundings (Cooper and Mason, 2000; Hansen et al., 2011), perhaps especially when awaiting the arrival of food, i.e. during our pre-feeding observation period. The uses to which mink put their preferred resting sites could potentially be identified by observing which specific sub-types of inactivity these promote (e.g. resting with eyes open vs. sleeping: Meagher et al., submitted for publication).

The causes of individual differences in E Manipulation also warrant further investigation. Low E Manipulation among highly stereotypic animals did not seem to reflect low behavioural flexibility (cf. e.g. Coppens et al., 2010): E Manipulation was not closely related to recurrent perseveration; and, furthermore, these animals did alter their behaviour in a major way after being moved to Enriched housing, as we have seen, by greatly reducing their SBs and choosing to rest in previously inaccessible areas. Differential neophobia (fear of novelty) could be another cause: neophobia predicted infrequent enrichment use in mice housed similarly to our mink, with an extra enriched cage available at the end of a length of PVC tubing (Walker and Mason, 2011). However, as mentioned, highly stereotypic mink are not typically the most timid (Hansen and Jeppesen, 2006). A related outstanding question is: why did formerly very inactive animals show the most frequent direct interactions with enrichment objects and water when given the opportunity? Do these individuals interact with enrichments more than others because they are more strongly motivated to do so (cf. Hanmer et al., 2010)? 
Could highly inactive animals even find NE environments particularly understimulating or 'boring' (Meagher, 2011; Meagher and Mason, in press)?

Two methodological oversights deserve mention. First, we failed to capture the full strength of motivation to reach all enriched areas, because one tower and part of the tunnel were accessible without opening the weighted door. Assessments of motivational strength using weighted doors should now locate those doors with care - immediately outside the home cage if motivations for all aspects of enriched housing are of interest; but physically separating enrichments offering opportunities for naturalistic activity from elevated tunnels, if the aim is to assess the relative motivations for these independently. Despite this, our experiment did show that mink were as highly motivated to reach the enriched compartment as they were to reach food, and that assessing the breakage of a paper strip by mink opening a weighted door can be a practical, easy way to assess the point at which the 'maximum price paid' point is reached (cf. Tilly et al., 2010). Second, in following our facility's standard feeding practice, we did not experimentally standardize food consumption, even though hunger can play an important causal role in SB (e.g. Damgaard et al., 2004). Our patterns of results did not change when we reanalysed our data controlling for food consumption in Enriched housing, or after removing two outliers who seemed to be both very stereotypic and particularly ravenous. Nevertheless, any future study would be advised to adjust the amount of food provided to each mink according to individual consumption levels (e.g. Damgaard et al., 2012; Hansen et al., 2011), to avoid the possibility of differential hunger adding noise.

The welfare implications of the individual differences revealed in this study need further investigating: future work should test the hypotheses that the welfare of highly stereotypic mink is most improved by the provision of alternative resting places, while the welfare of inactive mink is instead most improved by the provision of manipulable objects and other opportunities for active behaviour. Furthermore, the generality of these individual differences now needs to be explored in other species, particularly in Carnivora displaying pacing or similar SBs: do subjects with high and low levels of SB react differently to different types of enrichment?

\section{Conclusion}

SB is a management concern for many reasons, across a wide range of species, not least because it can indicate that housing and husbandry are inadequate for welfare. Well over 85 million captive animals perform SB worldwide, including tens of millions of mink (Mason and Latham, 2004) and thousands of other Carnivora with locomotor SBs (Mason et al., 2007): the number of animals who could potentially benefit from EE is thus extremely large. Despite this, studies of why some individuals benefit more than others, at least in terms of SB reduction, are still in their infancy. Our data suggest that the 'establishment' of SB does not help explain this effect, and nor does perseveration. Better predictors proved to be whether enrichment items were used for active interactions, or instead whether newly accessible aspects of the apparatus were used for new forms of inactivity - responses that were in turn predicted by whether mink were respectively minimally or highly stereotypic before enrichments were provided. A better scientific understanding of inter-individual differences in responses to different EEs could therefore eventually help us identify those cases where the husbandry of certain individuals will require extra effort, or individually customized environmental enrichments.

\section{Acknowledgments}

We wish to thank Angelo Napolitano and the Michigan State Experimental Fur Farm staff. We are grateful to María Díez-León and two anonymous reviewers for their helpful and thought-provoking comments. Funding was provided by an NSERC Discovery grant to GJM, and NSERC post-graduate scholarship to JAD and RKM.

\section{References}

Akre, A.K., Hovland, A.L., Bakken, M., Braastad, B.O., 2008. Risk assessment concerning the welfare of animals kept for fur production: a report to the Norwegian Scientific Committee for Food Safety. Norwegian University of Life Sciences, Ås, Norway.

Axelsson, H.M.K., Aldén, E., Lidfors, L., 2009. Behaviour in female mink housed in enriched standard cages during winter. Appl. Anim. Behav. Sci. 121, 222-229.

Bergeron, R., Badnell-Waters, A.J., Lambton, S., Mason, G., 2006. Stereotypic oral behaviour in captive ungulates: foraging, diet and gastrointestinal function. In: Mason, G., Rushen, J. (Eds.), Stereotypic Animal Behaviour: Fundamentals and Applications to Welfare. CABI, Wallingford, England, pp. 121-152.

Bildsøe, M., Heller, K.E., Jeppesen, L.L., 1991. Effects of immobility stress and food restriction on stereotypies in low and high stereotyping female ranch mink. Behav. Process. 25, 179-189.

Brennan, K., Roberts, D.C.S., Anisman, H., Merali, Z., 2001. Individual differences in sucrose consumption in the rat: motivational and neurochemical correlates of hedonia. Psychopharmacologia 157, 269-276.

Burghardt, G., 2005. The Genesis of Animal Play: Testing the Limits. MIT Press, Cambridge.

Carlstead, K., Brown, J.L., Seidensticker, J., 1993. Behavioral and adrenal responses to environmental changes in leopard cats (Felis bengalensis). Zoo Biol. 12, 321-331.

Clubb, R., Vickery, S., 2006. Locomotory stereotypies in carnivores: does pacing stem from hunting, ranging or frustrated escape? In: Mason, G., Rushen, J. (Eds.), Stereotypic Animal Behaviour: Fundamentals and Applications to Welfare. CABI, Wallingford, England, pp. 58-85.

Cooper, J.J., Mason, G.J., 2000. Increasing costs of access to resources cause re-scheduling of behaviour in American mink(Mustela vison): implications for the assessment of behavioural priorities. Appl. Anim. Behav. Sci. 66, 135-151.

Cooper, J.J., Mason, G.J., 2001. The use of operant technology to measure behavioral priorities in captive animals. Behav. Res. Methods 33, 427-434.

Cooper, J.J., Ödberg, F., Nicol, C.J., 1996. Limitations on the effectiveness of environmental improvement in reducing stereotypic behaviour in bank voles (Clethrionomys glareolus). Appl. Anim. Behav. Sci. 48, 237-248.

Coppens, C.M., de Boer, S.F., Koolhaas, J.M., 2010. Coping styles and behavioural flexibility: towards underlying mechanisms. Philos. Trans. R. Soc. Lond. B: Biol. Sci. 365, 4021-4028.

Cosyns, P., Ödberg, F., 2000. Obsessive compulsive disorders: clinical hallmarks and animal models. Neurosci. Res. Commun. 26, 301-310.

Cronin, G.M., 1985. The development and significance of abnormal stereotyped behaviours in tethered sows, $\mathrm{PhD}$ thesis. Agricultural University of Wageningen, The Netherlands.

Dallaire, J.A., Meagher, R.K., Díez-León, M., Garner, J.P., Mason, G.J., 2011. Recurrent perseveration correlates with abnormal repetitive locomotion in adult mink but is not reduced by environmental enrichment. Behav. Brain Res. 224, 213-222. 
Damgaard, B.M., Hansen, S.W., Børsting, C.F., Møller, S.H., 2004. Effects of different feeding strategies during the winter period on behaviour and performance in mink females (Mustela vison). Appl. Anim. Behav. Sci. $89,163-180$

Damgaard, B.M., Dalgaard, T.S., Larsen, T., Hedemann, M.S., Hansen, S.W., 2012. The effects of feed restriction on physical activity, body weight, physiology, haematology and immunology in female mink. Res. Vet. Sci. 93, 936-942.

Darlington, R.B., Smulders, T.V., 2001. Problems with residual analysis. Anim. Behav. 62, 599-602.

Dawkins, M.S., 1983. Battery hens name their price: consumer demand theory and the measurement of ethological 'needs'. Anim. Behav. 31 1195-1205.

Díez-León, M., Mason, G., 2010. Male mink (Mustela vison) from enriched cages are more successful as mates. In: Lidfors, L., Blokhuis, N., Keeling, L. (Eds.), Proceedings of the 44th Congress of the International Society for Applied Ethology, Uppsala, Sweden, 4-7 August 2010. Wageningen Academic Publishers, The Netherlands, p. 96.

Dodman, N.H., Karlsson, E.K., Moon-Fanelli, A., Galdzicka, M., Perloski, M., Shuster, L., Lindblad-Toh, K., Ginns, E.I., 2010. A canine chromosome 7 locus confers compulsive disorder susceptibility. Mol. Psychiatry 15 , $8-10$.

Dunstone, N., 1993. The Mink. T. \& A.D. Poyser Ltd., London.

García-Berthou, E., 2001. On the misuse of residuals in ecology: testing regression residuals vs. the analysis of covariance. J. Anim. Ecol. 70, 708-711.

Garner, J.P., Mason, G.J., 2002. Evidence for a relationship between cage stereotypies and behavioural disinhibition in laboratory rodents. Behav. Brain Res. 136, 83-92.

Gibbons, J.M., Lawrence, A.B., Haskell, M.J., 2010. Measuring sociability in dairy cows. Appl. Anim. Behav. Sci. 122, 84-91.

Hadley, C., Hadley, B., Ephraim, S., Yang, M., Lewis, M.H., 2006. Spontaneous stereotypy and environmental enrichment in deer mice (Peromyscus maniculatus): reversibility of experience. Appl. Anim. Behav. Sci. 97, 312-322.

Hanmer, L.A., Riddell, P.M., Williams, C.M., 2010. Using a runway paradigm to assess the relative strength of rats' motivations for enrichment objects. Behav. Res. Methods 42, 517-524.

Hansen, S.W., 1990. Activity pattern of lactating mink and the effect of water trays or wire netting cylinder in mink cages. Scientifur 14 187-193.

Hansen, C.P.B., Jeppesen, L.L., 2000. Short term behavioural consequences of denied access to environmental facilities in mink. Agric. Food Sci. Finland 9, 149-155.

Hansen, S.W., Jeppesen, L.L., 2006. Temperament, stereotypies and anticipatory behaviour as measures of welfare in mink. Appl. Anim. Behav. Sci. 99, 172-182.

Hansen, S.W., Malmkvist, J., Palme, R., Damgaard, B.M., 2007. Do double cages and access to occupational materials improve the welfare of farmed mink? Anim. Welf. 16, 63-76.

Hansen, S.W., Møller, S.H., Damgaard, B.M., 2011. Feed restriction and tubes for environmental enrichment in growing mink - consequences for behaviour and welfare. Appl. Anim. Behav. Sci. 134, 193-200.

Houbak, B., Jeppesen, L.L., 1987. Adfaerd i forbindelse med fravaenning hos mink. In: Faglig arsberetning. Danish Fur Breeders Association, Denmark, pp. 134-142.

Hovland, A.L., Mason, G., Bøe, K.E., Steinheim, G., Bakken, M., 2006. Evaluation of the 'maximum price paid' as an index of motivational strength for farmed silver foxes (Vulpes vulpes). Appl. Anim. Behav. Sci. 100, 258-279.

Kastelein, R.A., Wiepkema, P.R., 1989. A digging trough as occupational therapy for Pacific Walrusses (Odobenus rosmarus divergens) in human care. Aquat. Mamm. 15, 9-17.

Kirkden, R.D., Pajor, E.A., 2006. Using preference, motivation and aversion tests to ask scientific questions about animals' feelings. Appl. Anim. Behav. Sci. 100, 29-47.

Kirkden, R.D., Edwards, J.S.S., Broom, D.M., 2003. A theoretical comparison of the consumer surplus and the elasticities of demand as measures of motivational strength. Anim. Behav. 65, 157-178.

Latham, N., Mason, G., 2010. Frustration and perseveration in stereotypic captive animals: is a taste of enrichment worse than none at all? Behav. Brain Res. 211, 96-104.

Lumeij, J.T., Hommers, C.J., 2008. Foraging 'enrichment' as treatment for pterotillomania. Appl. Anim. Behav. Sci. 111, 85-94.
Martin, P., Bateson, P., 2007. Measuring Behaviour: An Introductory Guide, third ed. Cambridge University Press, Cambridge.

Mason, G.J., 1993. Age and context affect the stereotypies of caged mink. Behaviour 127, 191-229.

Mason, G., 2006. Stereotypic behaviour in captive animals: fundamentals and implications for welfare and beyond. In: Mason, G., Rushen, J. (Eds.), Stereotypic Animal Behaviour: Fundamentals and Applications to Welfare. CABI, Wallingford, England, pp. 325-356.

Mason, G.J., Latham, N.R., 2004. Can't stop, won't stop: is stereotypy a reliable animal welfare indicator? Anim. Welf. 13, S57-S69.

Mason, G., Cooper, J., Clarebrough, C., 1999. Using techniques from human economics to measure what animals value, as illustrated by experimental work on the American mink (Mustela vison). In: Hare, V.J., Worley, K.E., Myers, K. (Eds.), Proceedings of the Fourth International Conference on Environmental Enrichment, Edinburgh, Scotland, 29 August-3 September 1999. The Shape of Enrichment, Edinburgh, pp. 111-117.

Mason, G.J., Cooper, J., Clarebrough, C., 2001. Frustrations of fur-farmed mink. Science 410, 35-36.

Mason, G., Clubb, R., Latham, N., Vickery, S., 2007. Why and how should we use environmental enrichment to tackle stereotypic behaviour? Appl. Animal. Behav. Sci. 102, 163-188.

Meagher, R.K., 2011. The welfare significance of inactivity in captive animals, using mink as a model. PhD thesis, University of Guelph, Canada.

Meagher, R.K., Mason, G.J, Environmental enrichment reduces signs of boredom in caged mink. PLoS One, http://dx.doi.org/ 10.1371 /journal.pone.0049180, in press.

Meagher, R.K., Campbell, D.L., Ahloy Dallaire, J., Díez-León, M., Palme, R. Mason, G.J., Sleeping tight or hiding in fright? The welfare implications of different subtypes of inactivity in mink. Appl. Anim. Behav. Sci., submitted for publication (accepted pending minor revision; submitted July 18, 2012; MS\#: Applan-D-12-229). 34 pages.

Meehan, C.L., Garner, J.P., Mench, J.A., 2004. Environmental enrichment and development of cage stereotypy in orange-winged amazon parrots (Amazona amazonica). Dev. Psychobiol. 44, 209-218.

Meyer-Holzapfel, M., 1968. Abnormal behavior in zoo animals. In: Fox, M.W. (Ed.), Abnormal Behavior in Animals. Saunders, London, pp. 476-503.

Ödberg, F., 1978. Abnormal behaviors: (stereotypies). In: Garsi, J. (Ed.) Proceedings of the 1st World Congress on Ethology Applied to Zootechnics, Madrid, Spain, 23-27 October 1978. Industrias Graficas Espańa, Madrid, Spain, pp. 475-480.

Olsson, I.A.S., Keeling, L.J., 2002. The push-door for measuring motivation in hens: laying hens are motivated to perch at night. Anim. Welf. 11, 11-19.

Seaman, S.C., Waran, N.K., Mason, G., D’Eath, R.B., 2008. Animal economics: assessing the motivation of female laboratory rabbits to reach a platform, social contact and food. Anim. Behav. 75, 31-42.

Shyne, A., 2006. Meta-analytic review of the effects of enrichment on stereotypic behavior in zoo mammals. Zoo Biol. 25, 317-337.

Svendsen, P.M., Hansen, S.W., Jeppesen, L.L., 2007. Direct scan sampling reliable reflects video recorded differences in stereotypy in selected lines of mink. Scientifur 31, 19-25.

Swaisgood, R., Shepherdson, D., 2006. Environmental enrichment as a strategy for mitigating stereotypies in zoo animals: a literature review and meta-analysis. In: Mason, G., Rushen, J. (Eds.), Stereotypic Anima Behaviour: Fundamentals and Applications to Welfare. CABI, Wallingford, England, pp. 121-152.

Tilly, S.L.C., Dallaire, J., Mason, G.J., 2010. Middle-aged mice with enrichment-resistant stereotypic behaviour show reduced motivation for enrichment. Anim. Behav. 80, 363-373.

Vickery, S.S., 2003. Stereotypic behaviour in caged bears: individual and husbandry factors. PhD thesis, University of Oxford, UK.

Walker, M.D., Mason, G., 2011. Female C57BL/6 mice show consistent individual differences in spontaneous interaction with environmental enrichment that are predicted by neophobia. Behav. Brain Res. 224 207-212.

Wielebnowski, N.C., Fletchall, N., Carlstead, K., Busso, J.M., Brown, J.L., 2002. Noninvasive assessment of adrenal activity associated with husbandry and behavioral factors in the North American clouded leopard population. Zoo Biol. 21, 77-98.

Würbel, H., 2006. The motivational basis of caged rodents' stereotypies. In: Mason, G., Rushen, J. (Eds.), Stereotypic Animal Behaviour: Fundamentals and Applications to Welfare. CABI, Wallingford, England, pp. 86-120. 